\title{
Research on the Failure and Fracture Evolution of Mylonite with a Prefabricated Circular Opening by Discrete Element Method
}

\author{
Kunmeng Li, ${ }^{1}$ Yuanhui Li $\mathbb{D}^{1,2}$ Shuai $X u,{ }^{1}$ Zhipeng Xiong, ${ }^{1}$ and Long $\mathrm{An}^{1}$ \\ ${ }^{1}$ Key Laboratory of Ministry of Education on Safe Mining of Deep Metal Mines, Northeastern University, \\ Shenyang 110819, China \\ ${ }^{2}$ China-Canada Centre of Deep Mining Innovation, \\ Key Laboratory of Ministry of Education on Safe Mining of Deep Metal Mines, Northeastern University, Shenyang 110819, \\ Liaoning, China \\ Correspondence should be addressed to Yuanhui Li; 877260351@qq.com
}

Received 15 January 2021; Revised 2 April 2021; Accepted 22 April 2021; Published 12 May 2021

Academic Editor: Chunyang Zhang

Copyright (c) 2021 Kunmeng Li et al. This is an open access article distributed under the Creative Commons Attribution License, which permits unrestricted use, distribution, and reproduction in any medium, provided the original work is properly cited.

In this paper, the failure and fracture process of mylonite with a prefabricated circular opening under biaxial loading is studied by $\mathrm{PFC}^{2 \mathrm{D}}$ code. Firstly, the hoop stress change law of opening wall in the process of loading is theoretically analyzed and three fracture patterns of rocks are proposed. Secondly, the biaxial loading tests of mylonite for numerical simulation are carried out, and the failure and fracture are analyzed from three aspects of space-time evolution of microcracks, energy conversion process, and final damage patterns. As the load progresses, the microcracks start to initiate at the side wall of the opening and the growth velocity of microcracks develops from the slow to fast and then slows down again. The final damage pattern of mylonite with a prefabricated circular opening belongs to shear fracture. The fracture zones start with the side wall spalling and then gradually extend to the border of the rock, which widen from the opening boundary to the border of the rock and slightly twist in the middle. The final fault zone width is about 6 times wider than the average size of simulation particles. Finally, based on the uniaxial compressive strength of mylonite in the laboratory, it is inferred that the fracture pattern of mylonite with a prefabricated circular opening by theoretical analysis is indeed shear failure, which is consistent with the result of numerical simulation.

\section{Introduction}

In recent years, with the continuous depletion of shallow mineral resources and global environmental agitations against mining, deep mining is becoming the development trend in the future. With the increase in mining depth, engineering geological disasters will become more frequent $[1,2]$, such as roof falling, side wall slabbing, and rock blasting. In order to ensure the safe and efficient mining of deep orebodies, it is essential to study the failure and fracture evolution mechanism of the surrounding rock mass after the orebody is mined [3-7].

Although the on-site monitoring results of the rock mass responses with mining operations are more reliable [8-10], the field industrial test is time-consuming and labor-intensive, making it difficult to achieve. In contrast, laboratory and numerical simulation tests for small-sized rocks are easy to control the loading and boundary condition and set up more monitors, and the failure evolution process and the final fracture pattern of actual excavated rock mass can be correctly speculated according to the laboratory and numerical simulation tests [11-18]. Therefore, laboratory and numerical simulation tests for small-sized rocks have become the mainstream to study the damage mechanism of rock mass around underground excavation $[19,20]$.

Throughout the experimental studies of rocks with prefabricated openings in the whole world, it is shown that under the uniaxial compression condition, the ultimate damage pattern of the rock with a circular opening mainly presents the tensile fractures at the top and bottom of the opening paralleling to the loading orientation, the compression fractures are produced on both sides of the opening, 
and the far-field failures occurs around the opening [12, 21]. However, the final damage patterns cannot be characterized as the whole failure process of rocks, which includes the initiation, growth, and coalescence of microcracks. Compared with the physical experiment in the laboratory, numerical simulation can reproduce the failure evolvement of rocks during the loading process, and it not only can be used to analyze the failure and fracture mechanism of rocks from different aspects but also the numerical simulation tests can be repeated to generate the reliable results $[11,21,22]$. If the numerical model can be accurately calibrated, the results will provide a guide for better forward prediction of the behaviors of engineering structures in rock mass.

At present, continuum model and discrete element method (DEM) are commonly adopted to simulate the damage and deformation behaviors of rocks [11, 23]. Compared with the continuum model, DEM does not involve the division of grids, so the mesh size sensitivity of grids does not need to be considered. DEM generates macroscopic response by the superimposition of mechanical behaviors among microscopic unit bodies, which saves the effort of presetting complex mathematical constitutive relationship into the model. The particle flow code $\mathrm{PFC}^{2 \mathrm{D}}$ based on the DEM can well simulate the local anisotropic behaviors of rocks during the loading process and can reproduce the space-time evolution of microcracks and the eventual fracture zones so which is therefore widely adopted to study the mechanical behaviors of various of rock mass [24] which utilized $\mathrm{PFC}^{2 \mathrm{D}}$ to predict the fracture zones of the Canadian underground laboratory. Potyondy and Autio [25] simulated the damage pattern of gneiss with an excavated circular opening during uniaxial compression process. Fakhimi et al. [11] conducted biaxial loading simulation tests of granite with a pre-existing circular opening, and the microcracks development results by numerical simulation and acoustic emission test were consistent. Fan et al. [26] used the PFC program to establish numerical models containing one open flaw and two circular openings. Cao et al. [27] researched the mechanical behavior of an opening in a jointed rock-like specimen under uniaxial loading by experimental studies and particle mechanics approach. The above studies have confirmed that $\mathrm{PFC}^{2 \mathrm{D}}$ software can successfully simulate the mechanical behaviors of rocks with loading. However, previous studies have certain limitations as on the one hand they did not consider the differences in terms of rock type; on the other hand, they are relatively lack of the analysis of rock failure mechanism, therefore which cannot be accepted in predictions of the failure evolution mechanism of the other rocks.

The surrounding rock mass in the footwall at -850 depth in a Chinese gold mine mainly belongs to the mylonite, which is a kind of metamorphic rock, and the stability is relatively good. In this paper, the mylonite is taken as the research object, and the failure and fracture process of mylonite with a prefabricated circular opening is researched under the biaxial loading condition by PFC2D. The simulated results are analyzed from three aspects: space-time evolution of microcracks, energy conversion process, and the final fracture patterns.

\section{Theoretical Analyses}

In order to understand the failure and fracture mechanism of mylonite with a prefabricated circular opening under the biaxial loading condition, the elastic stress state of the rock is calculated by Equations (1) to (4) [28]. Figure 1 shows the geometric loading condition of the rock, and the boundary stresses in vertical and horizontal directions are, respectively, shown as $P_{0}$ and $\lambda P_{0}$, where $\lambda$ is the lateral pressure coefficient. Based on the theory of elasticity, the radial, hoop, and tangential stresses [28] of the rock around the circular opening are calculated, respectively, as following formulas:

$$
\begin{aligned}
& \sigma_{r}=\frac{1}{2}(1+\lambda) P_{0}\left(1-\frac{R_{0}^{2}}{r^{2}}\right)-\frac{1}{2}(1-\lambda) P_{0}\left(1-4 \frac{R_{0}^{2}}{r^{2}}+3 \frac{R_{0}^{2}}{r^{4}}\right) \cos 2 \theta, \\
& \sigma_{\theta}=\frac{1}{2}(1+\lambda) P_{0}\left(1+\frac{R_{0}^{2}}{r^{2}}\right)+\frac{1}{2}(1-\lambda) P_{0}\left(1+3 \frac{R_{0}^{2}}{r^{4}}\right) \cos 2 \theta, \\
& \tau_{\mathrm{r} \theta}=\frac{1}{2}(1-\lambda) P_{0}\left(1+2 \frac{R_{0}^{2}}{r^{2}}-3 \frac{R_{0}^{2}}{r^{4}}\right) \cos 2 \theta,
\end{aligned}
$$

$$
\begin{aligned}
\sigma_{r} & =0, \\
\sigma_{\theta} & =(1+\lambda) P_{0}+2(1-\lambda) P_{0} \cos 2 \theta, \\
\tau_{r \theta} & =0 .
\end{aligned}
$$

stresses, respectively; $R_{0}$ is the radius of the circular opening; and $r$ is the distance from the opening center to the point for obtaining the stress state. It can be calculated that when $r=0$, the stress state at the wall of the circular opening is
As shown in Figure 2, during the biaxial loading tests of rocks, the lateral pressure coefficient $\lambda$ continuously 


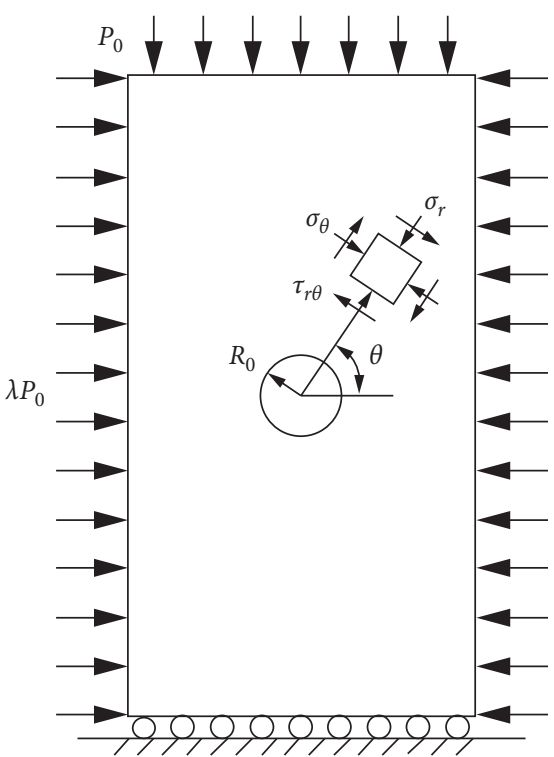

FIGURE 1: Geometric loading condition.

decreases with loading but which is always less than 1 . Corresponding to different $\lambda$, the distribution of hoop stresses on the circular opening wall of the rock is shown in Figure 3 [29]. The straight length which surrounds and is perpendicular to the opening represents the magnitude of hoop stresses on the opening wall. When the straight line is located inside the opening, it represents tensile stress, while when it is located outside the opening, it indicates compressive stress. It is apparent from Figure 3 that the reduction of $\lambda$ may result in the increase in compressive stresses on the two sides of the opening wall as well as the reduction of compressive stresses at the top and bottom of the opening wall. When $\lambda=1 / 3$, the hoop compressive stresses at the top and bottom of the opening wall are reduced to 0 , and the tensile stress begins to appear at the top and bottom of the opening wall along with continuous loading.

Based on the variation of hoop stresses on the opening wall during the biaxial loading process, it can be speculated that there are no more than three reasons that eventually lead to rock fractures. (1) When the tensile stresses at the top and bottom of the opening do not reach the peak strength while the compressive stresses on both sides of the opening have already reached the peak strength, only the shear fractures of rocks occur on both sides of the opening and the both sides of the opening spall and extend to the border with loading, as schematically shown in Figure 4(a). (2) When the compressive stresses on both sides of the opening do not reach the peak strength while the tensile stresses at the top and bottom of the opening have already reached them peak strength, the tensile fractures of rocks occur at the top and bottom of the opening and the top and bottom of the opening spall and extend to upper and lower ends with loading, as schematically shown in Figure 4(b). (3) When the compressive stresses on both sides of the opening and the tensile stresses at the top and bottom of the opening all reach the peak strength, the shear fractures of rocks occur on both

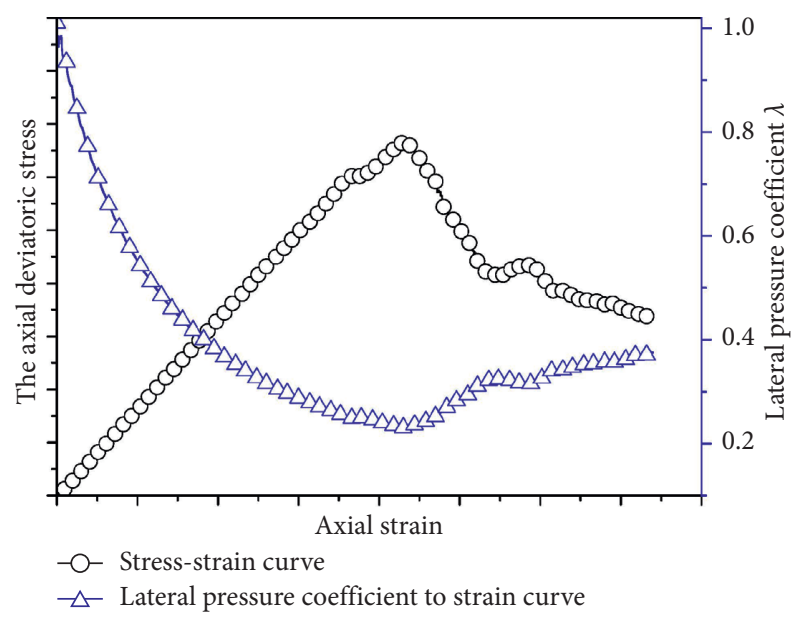

Figure 2: Conceptual axial deviatoric stresses with different $\lambda$.

sides of the opening and the tensile fractures of rocks occur at the top and bottom of the opening. Meanwhile, the both sides of the opening spall extend to the border and the top and bottom of the opening spall and extend to upper and lower ends, as schematically shown in Figure 4(c).

\section{Numerical Simulation}

When $\mathrm{PFC}^{2 \mathrm{D}}$ is applied to simulate the mechanical behaviors of rocks, the rock is modeled as a collection of circular particles for 3D or disks for 2D. The deformation of rocks is achieved by the positive and shear stiffness between particles, and the rock strength is controlled by additional contact bond keys and friction parameters. The formation of failures follows the Coulomb criterion, and the initiation of microcracks is consistent with the breaks of bond keys. The contact constitutive model between the particles is shown in Figure 5.

3.1. Determination of Microscopic Parameters. Before simulating the mechanical behaviors of specific types of rocks, $\mathrm{PFC}^{2 \mathrm{D}}$ needs to determine a set of particle microscopic parameters such as particle size distribution, contact stiffness, and strength between particles. The microscopic parameters of the numerical model are the basis for obtaining accurate simulation results. However, the mechanical behavior of rocks is commonly described by the elastic deformation constant, compressive strength, residual strength, and other macroscopic parameters. As the microscopic parameters of numerical simulation are nonlinear to the macroscopic response of laboratory tests, the microscopic parameters cannot be calculated directly by the macroscopic response.

In view of the blindness of "trial and error method" $[11,30]$ for determining the microscopic parameters of the $\mathrm{PFC}^{2 \mathrm{D}}$ numerical model, Li et al. [31] proposed a parameter determination method based on laboratory test response in the previous research. The geometry parameters of the numerical model are obtained by the basic characteristics of rocks. The contact constitutive parameters between particles 


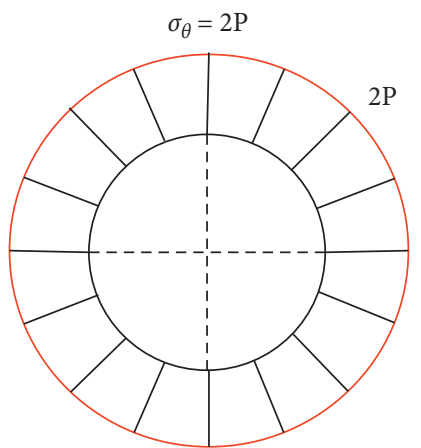

(a)

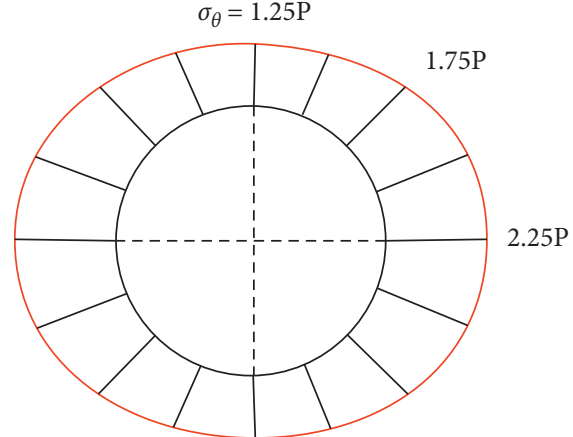

(b)

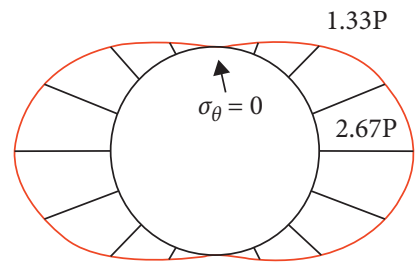

(c)

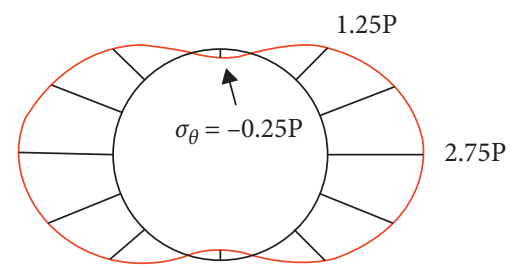

(d)

Figure 3: Hoop stresses distribution on the opening wall: (a) $\lambda=1.00$, (b) $\lambda=0.75$, (c) $\lambda=0.33$, and (d) $\lambda=0.25$.

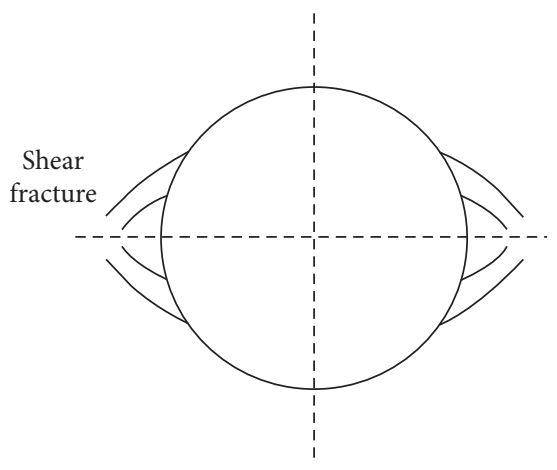

(a)

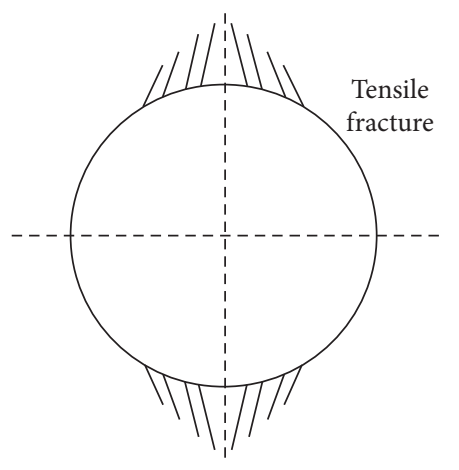

(b)

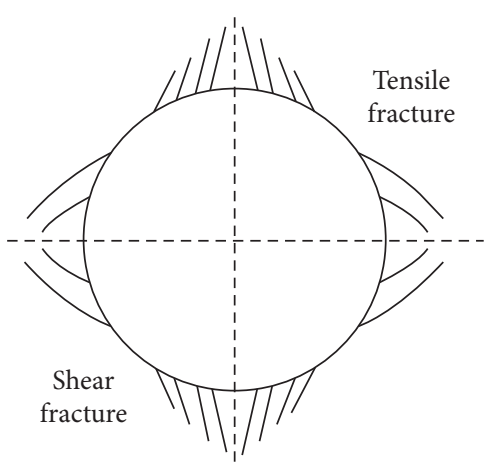

(c)

Figure 4: Final fracture patterns: (a) shear fractures, (b) tensile fractures, and (c) coexistence of shear and tensile fractures.

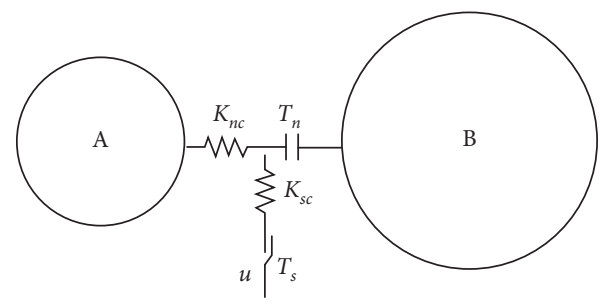

Figure 5: $\mathrm{PFC}^{2 \mathrm{D}}$ microscopic contact constitutive model.

are calculated by means of laboratorial test response, and the specific process can be summarized as the following steps. (1) The elastic modulus $E$, Poisson's ratio $v$, peak strength $\sigma_{c}$, initial failure strength $\sigma_{c i}$, and post-peak residual strength $\sigma_{\mathrm{ca}}$ of mylonite are obtained by the uniaxial or conventional triaxial physical test and which are, respectively, $3.48 e^{10} \mathrm{~Pa}$, $0.26,5.21 e^{7} \mathrm{~Pa}, 16.1 e^{6} \mathrm{~Pa}$, and $74.5 e^{6} \mathrm{~Pa}$. (2) On the basis of ensuring that the boundary, loading, and termination conditions are consistent with the physical tests, numerical simulation experiments are carried out. (3) The correspondence between the numerical simulation microscopic parameters and the macroscopic response is established by continuously changing the constitutive parameters in an orderly manner. (4) The specific values of various contact 
constitutive parameters are calculated according to the equal principle of macroresponse between numerical simulation and physical test. The detailed process can refer to the previous research [31]. As shown in Table 1, the determined microscopic parameters of mylonite located in the footwall of -850 depth in a Chinese gold mine can be described as the maximum and minimum radius ratio $R_{\max } / R_{\min }=1.66$, where $R_{\min }=0.2 \mathrm{e}^{-4} \mathrm{~m}$, and the particle radius satisfies uniform distribution, particle collection porosity $n=9 \%$, the density per unit volume $\rho=2630 \mathrm{~kg} / \mathrm{m}^{3}$, contact modulus between particles $E_{\mathrm{c}}=6 e^{10} \mathrm{MPa}$, positive stiffness and tangential stiffness ratio $K_{\mathrm{n}} / K_{\mathrm{s}}=4.5$, positive strength $T_{\mathrm{n}}=45 e^{6} \mathrm{MPa}$, positive strength to tangential strength $T_{\mathrm{n}} /$ $T_{\mathrm{s}}=1 / 5$, the strength deviations $T_{\mathrm{dn}} / T_{\mathrm{n}}$ and $T_{\mathrm{ds}} / T_{\mathrm{s}}$ are $1: 10$, and friction coefficient $u=0.5$. On the basis of the microscopic parameters, uniaxial and biaxial simulation experiments are carried out. As shown in Figure 6, the results show that the response of numerical simulation and laboratory test has a good consistency. Therefore, it is confirmed that the determined microscopic parameters are reliable and have strong applicability.

3.2. Numerical Model and Loading Condition. In order to simulate the failure evolution of rocks with the prefabricated circular opening, the rock sample is constructed in Figure $7(\mathrm{a})$, with height $\times$ width $=100 \mathrm{~mm} \times 50 \mathrm{~mm}$, and the diameter of the prefabricated circular opening is $10 \mathrm{~mm}$ and which is located in the center of sample. During the biaxial loading, a constant loading velocity $V_{\mathrm{p}}=1 e^{-3} \mathrm{~mm}$ is designed and the confining stress is kept as $10 \mathrm{MPa}$. The specific loading condition is shown as in Figure 7(b).

3.3. Results and Analysis. The failure and fracture evolution mechanism of mylonite with a prefabricated circular opening is analyzed from three aspects: space-time evolution of microcracks, energy conversion process, and the final fracture patterns. PFC ${ }^{2 \mathrm{D}}$ software identifies failures by monitoring the quantity of microcracks and drawing the microcracks with loading. Figure 8 shows the relationship between the quantity change of microcracks and the stressstrain curve during the biaxial loading test. Figure 9 is the spatial evolution process of microcracks, where the solid yellow line indicates breaks of the positive bonds and the solid red line represents breaks of the tangential bonds.

The results show that at the initial loading period, rocks with prefabricated openings are in the elastic deformation stage without cracks generation. As the load progresses, when the axial stress reaches the initial crack generation strength (about $73 \%$ of the peak strength), microcracks occur and the rock begins to enter the plastic deformation phase. Because of the concentration of compressive stress, shear cracks are created on both sides of the opening, as shown the red tangential bonds breaking in Figure 9(a). Before reaching the peak strength, microcracks are generated in a moderate speed, and the quantity of microcracks increases rapidly after the peak strength is reached and before the residual strength stabilizes when individual microcracks link and mutually merge, resulting that the rupture zones gradually generate and extend to the boundary of the rock, as shown in Figures 9(b) and 9(c). Meanwhile, the far-field cracks are formed and are far from the opening region. When the residual strength is stable, the fracture zones are basically shaped and the crack generation velocity slows down as well, as shown in Figure 9(d).

The rock loading process is often accompanied by the energy conversion. Figure 10 shows the evolution of different kinds of energies with loading. It can be seen that the whole loading process is mainly about the conversion of strain energy, border energy, and friction energy, and the variation trend of strain energy has a good correlation with axial stress-strain curve. The loading process can be divided into two stages from the perspective of energy conversion. Before the microcracks are generated, only border energy is converted into the strain energy, and the rock is in an elastic deformation stage. As the loading continues, a certain amount of border energy is further consumed and the crack is generated, and the coalescence of individual microcracks occurs and particles on the fracture regions begin to slip, causing that the friction energy increases. Meanwhile, the elastic strain energy at the rock damage zones is released. Therefore, the border energy mainly converts to the strain energy and friction energy. Before the peak strength is reached, the elastic strain energy of rock keeps increasing. However, as the elastic strain energy derived from border energy is not sufficient to offset its dissipation caused by extensive damage after the peak strength, the elastic strain energy starts to decrease. Before the residual intensity stabilizes, the strain energy decreases at a quite significant velocity, which is caused by the rapid generation of numerous microcracks at this stage, as shown the microcracks generation curve in Figure 8.

The failure evolution of mylonite with a circular opening extends from both sides of the opening to the boundary of the rock, as shown in Figure 9, and the final fracture pattern belongs to the shear failure. A central symmetric shear fracture zones are formed on the two sides of opening, whose direction is at an angle of $30^{\circ}$ from the axial loading direction. Figure 11 shows the enlarged view to the left of fracture zones in Figure 12(a), and the arrows represent the particle displacement field. The solid blue lines indicate breaks of the positive bonds, and the solid red lines represent breaks of the tangential bonds. The displacement field of the ultimate fault zones can be divided into three regions of A, B, and $\mathrm{C}$. In the region $\mathrm{A}$ and $\mathrm{C}$, the particle moving follows the standard rigid body motion, which is greatly different from the transition region $B$. The region $B$ is exactly the fault zone where particle displacement is almost zero and contains most of the microcracks. Meanwhile, the direction of microcracks is not exactly the same as that of the macroscopic fault zones. The fault width of region B keeps increasing from the opening to the border of rock, and the fault region slightly twists in the middle. The width of the fault zone is about six times wider than the average size of particles, i.e., the average diameter of particles is $0.532 \mathrm{~mm}$ and the average thickness of the fault is $3.2 \mathrm{~mm}$.

When the confining stress is $10 \mathrm{MPa}$, the relationship among the maximum compressive stress $\sigma_{\text {cmax }}$, the 
TABle 1: The microscopic parameters of the $\mathrm{PFC}^{2 \mathrm{D}}$ numerical model.

\begin{tabular}{lcccccccccc}
\hline Parameters & $R_{\max } / R_{\min }$ & $R_{\min }(\mathrm{m})$ & $\rho\left(\mathrm{kg} / \mathrm{m}^{3}\right)$ & $n(\%)$ & $E_{\mathrm{c}}(\mathrm{Pa})$ & $K_{\mathrm{n}} / K_{\mathrm{s}}$ & $T_{\mathrm{n}}(\mathrm{Pa})$ & $T_{\mathrm{n}} / T_{\mathrm{s}}$ & $\mathrm{T}_{\mathrm{dn}} / T_{\mathrm{n}}\left(\mathrm{T}_{\mathrm{ds}} / T_{\mathrm{s}}\right)$ & $u$ \\
\hline Value & 1.66 & $0.2 \mathrm{e}^{-4}$ & 2630 & 9 & $6 e^{10}$ & 4.5 & $45 e^{6}$ & $1 / 5$ & $1: 10$ & 0.5 \\
\hline
\end{tabular}

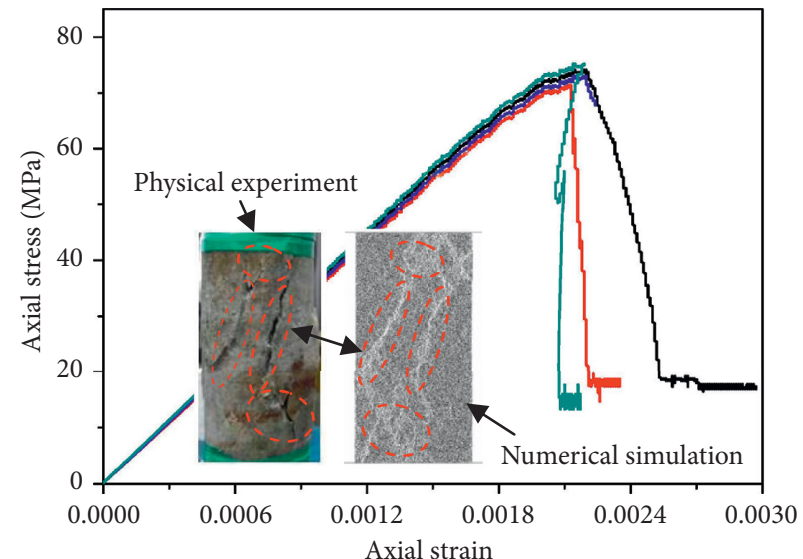

$\begin{array}{ll}\text { Numerical simulation } & - \text { Rock } 2 \text { of test } \\ \text { Rock } 1 \text { of test } & - \text { Rock } 3 \text { of test }\end{array}$

(a)

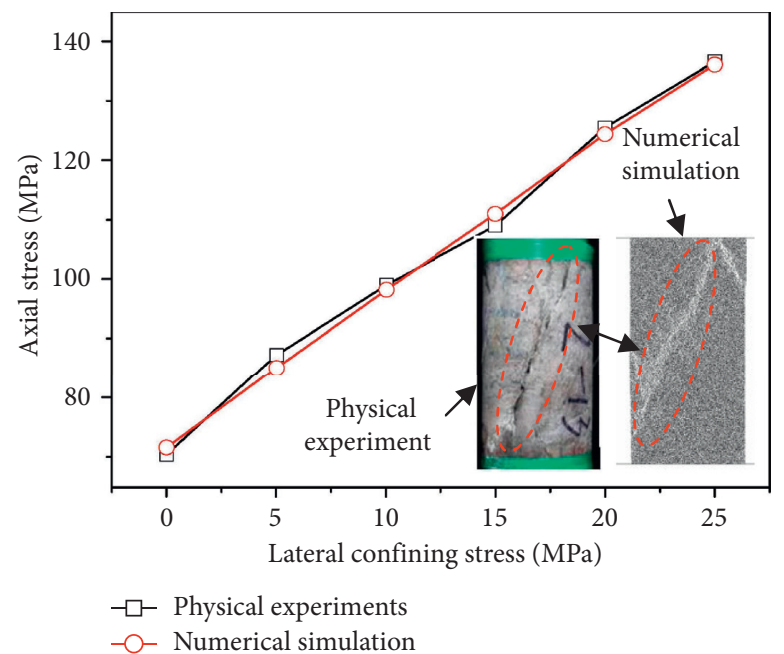

(b)

FiguRE 6: The compared results of physical experiments and numerical simulation: (a) uniaxial experiments and (b) biaxial experiments.

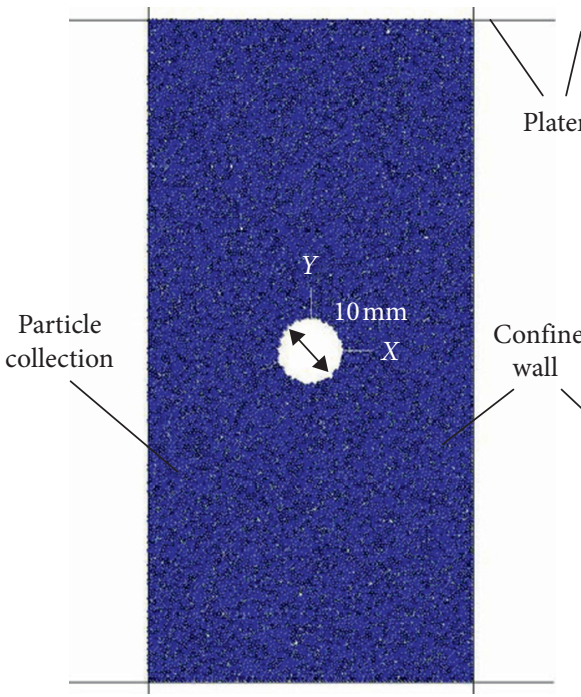

(a)

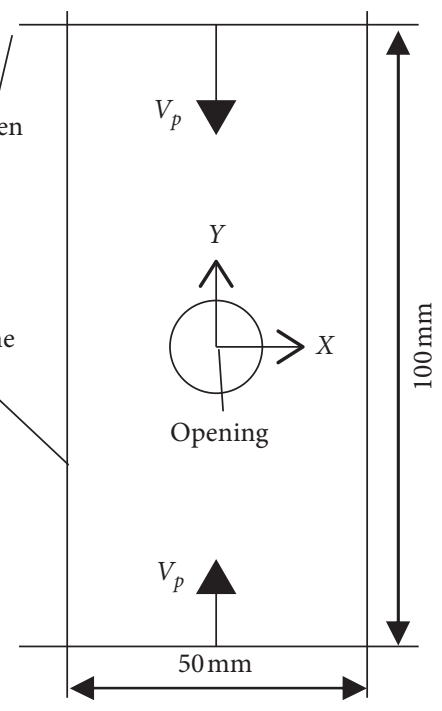

(b)

FIGURE 7: (a) The numerical model and (b) the loading condition.

maximum tensile stress $\sigma_{\text {tmax }}$, and the lateral pressure coefficient $\lambda$ of mylonite and sandstone are listed in Table 2 (corresponding to Figures 3(a)-3(d)) as the load progresses. The average uniaxial compressive strength of mylonite located in the footwall at -850 depth in a Chinese gold mine is $71.5 \mathrm{MPa}$ [31]. Therefore, when the axial stress reaches the compressive strength of the rock, there is still no tensile stress in the hoop stress on the opening wall, resulting that the final damage conforms to the first shear fracture pattern of theoretical analysis, as shown in Figure 4(a). The damage pattern of mylonite by theoretical analysis is consistent with numerical simulation, as shown in Figure 9. In order to further verify the three fracture patterns in Figure 4, the damage pattern of sandstone is evaluated. The uniaxial compressive strength of sandstone studied by Fakhimi et al. [11] was about $43 \mathrm{MPa}$, and when the axial stress reaches the compressive strength of the rock, tensile failure still does not occur. Therefore, the ultimate damage pattern of sandstone is shear fracture, which compares well with the physical experiment, as shown in Figure 12(c) and Table 2. 


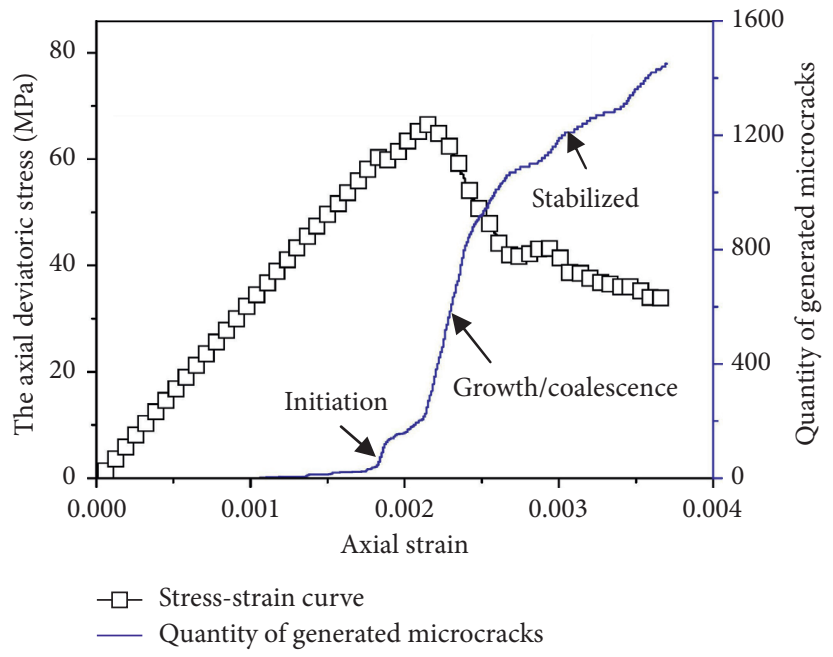

FIGURE 8: Relationship between the quantity of microcracks and axial stress-strain curve.

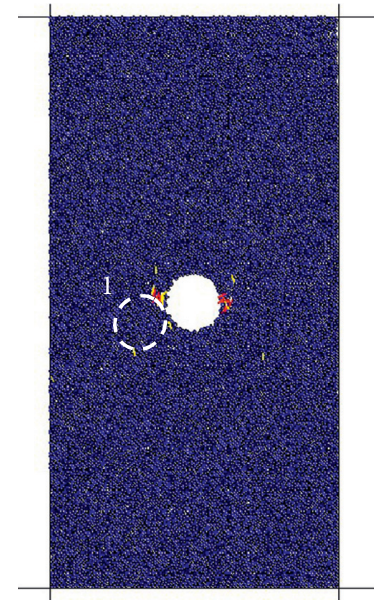

(a)

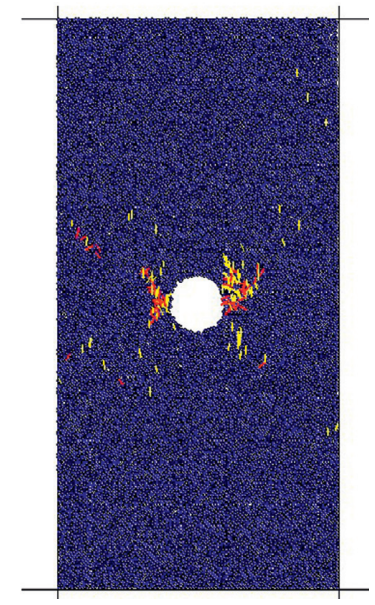

(b)

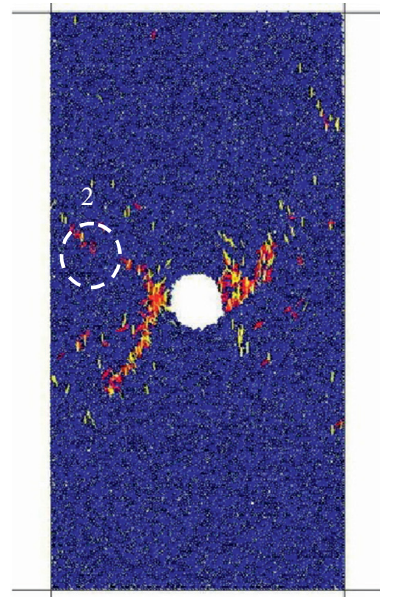

(c)

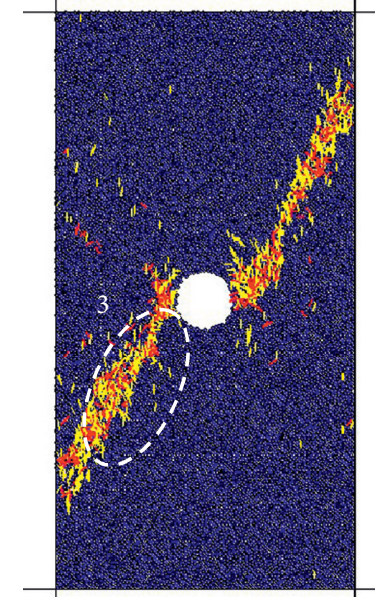

(d)

FIGURE 9: Space-time evolution process of microcracks during loading: (a) 85,000 step before peak, (b) 94,120 step at peak, (c) 100,000 step after peak, and (d) 109,120 step after peak. 1: notch fractures; 2: far-field fractures; 3: shear damage.

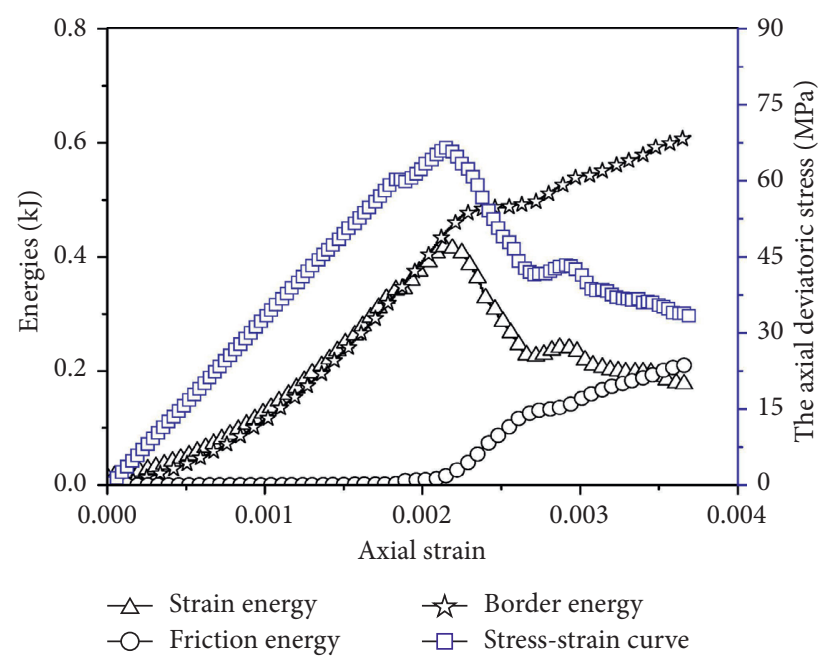

Figure 10: The changes of different energies. 


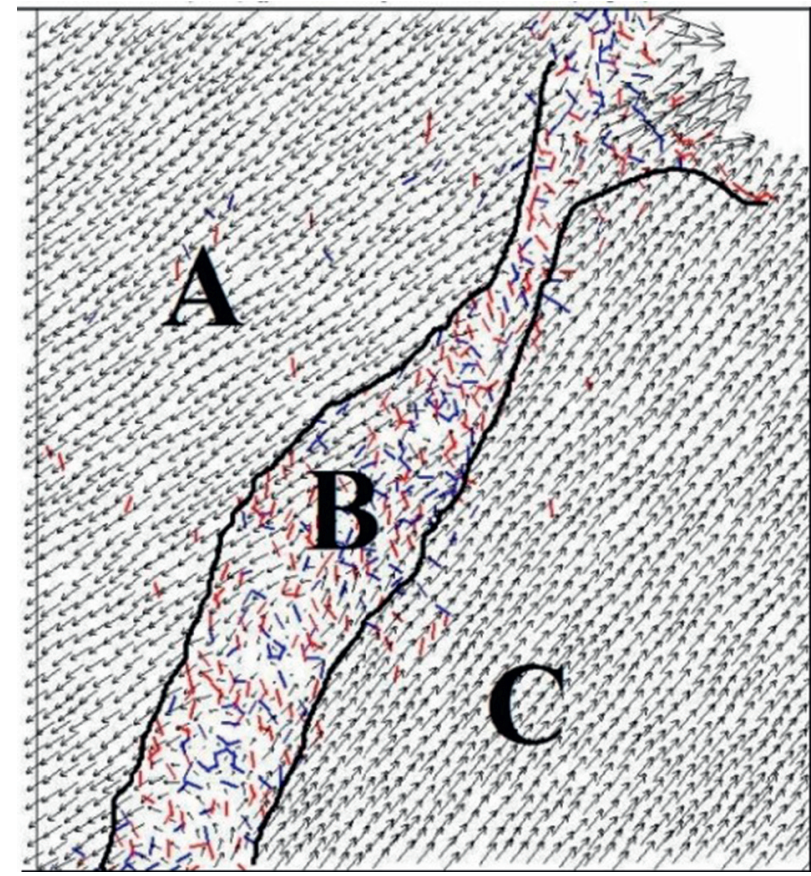

FIGURE 11: Microstructure of the fault zones after loading.

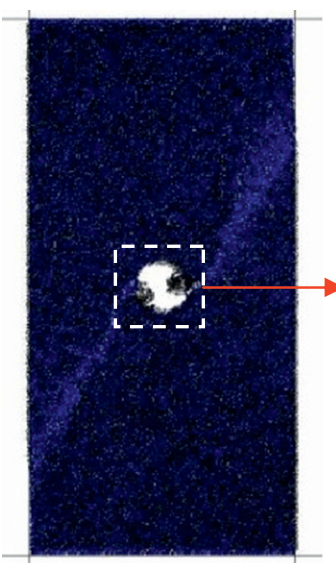

(a)

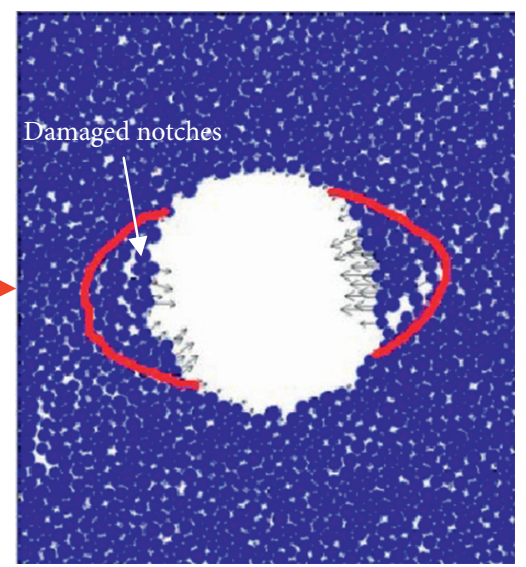

(b)

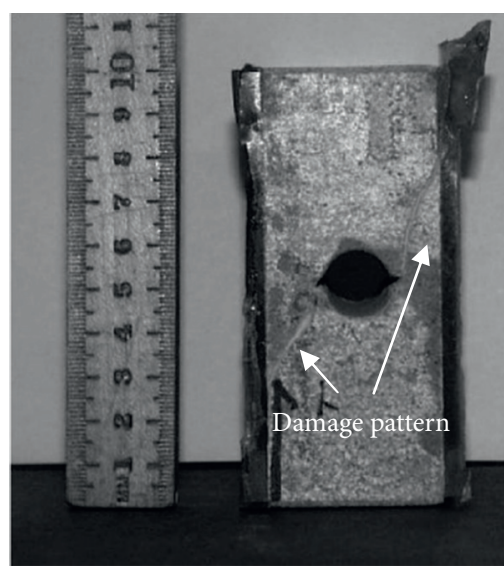

(c)

Figure 12: The fault zones and notch formation: (a) the displacement field, (b) the damaged notches near the opening, and (c) the sandstone fault pattern [11].

TABle 2: Statistics of the maximum compressive stress and the maximum tensile stress with different $\lambda$.

\begin{tabular}{lccccc}
\hline Lithology & $\lambda$ & 1 & 0.75 & 0.33 & 0.25 \\
\hline \multirow{2}{*}{ Mylonite } & $\sigma_{\text {cmax }} / \mathrm{MPa}$ & 20 & 30 & 79.5 & 110 \\
& $\sigma_{\text {tmax }} / \mathrm{MPa}$ & 0 & 0 & 0 & 10 \\
\hline \multirow{2}{*}{ Sandstone } & $\sigma_{\text {cmax }} / \mathrm{MPa}$ & 7.5 & 22.5 & 60.075 & 82.5 \\
& $\sigma_{\text {tmax }} / \mathrm{MPa}$ & 0 & 0 & 0 & 7.5 \\
\hline
\end{tabular}

\section{Conclusion}

In this paper, the failure and fracture mechanism of mylonite with a prefabricated circular opening is studied. From the perspective of theoretical analysis, three kinds of fracture patterns of the rock with a circular opening are proposed, that is, shear fractures at the sides of the opening, tensile fractures at the top and bottom of the opening, and the coexistence of shear and tensile fractures. In the biaxial loading process of mylonite with a prefabricated circular opening, the microcracks initiate on the side wall of opening when the loading stress is of about $73 \%$ of the peak strength with a $10 \mathrm{MPa}$ confining stress. The fracture zones mainly start to spall from the side wall and then gradually extend to the border of the rock. In terms of energy conversion, the process of rock fractures can be divided into two stages. Before the generation of microcracks, only the border energy is converted into the elastic strain energy of the rock, while after the microcracks begin to appear, the border energy is transformed into strain energy and friction energy. After the test load is completed, the fault zones widen and slightly 
twist in the middle from the opening boundary to the border of the rock, and the fault zone width is about six times wider than the average size of simulation particles. According to the uniaxial compressive strength of mylonite in laboratory tests, when the loading stress reaches the peak compressive strength, there is no hoop tensile stress on the opening side wall, so the final fracture pattern of mylonite should be the shear failure pattern, which coincides with the numerical simulation.

\section{Data Availability}

The data used to support the findings of this study are included within the article.

\section{Conflicts of Interest}

The authors declare that they have no conflicts of interest.

\section{Acknowledgments}

This work was supported by the State Key Research Development Program of China (grant numbers 2018YFC0604601 and 2018YFC0604405), the National Natural Science Foundation of China (grant numbers 52004054 and 51874068), the Program for Innovative Talents in Liaoning University (grant number LR2016024), and the Fundamental Research Funds for the Central Universities (grant numbers N180701016, N2001001, and N182608003).

\section{References}

[1] B. G. White, "Shear mechanism for mining-induced fractures applied to rock mechanics of coal mines," in Proceedings of the 2002 21st International Conference on Ground Control in Mining, pp. 328-334, Morgantown, WV, USA, August 2002.

[2] R. T. Ewy and N. G. W. Cook, "Deformation and fracture around cylindrical openings in rock-I. Observations and analysis of deformations," International Journal of Rock Mechanics and Mining Sciences \& Geomechanics Abstracts, vol. 27, no. 5, pp. 387-407, 1990.

[3] F.-Q. Gong, Y. Luo, X.-B. Li, X.-F. Si, and M. Tao, "Experimental simulation investigation on rockburst induced by spalling failure in deep circular tunnels," Tunnelling and Underground Space Technology, vol. 81, pp. 413-427, 2018.

[4] Y. Luo, F. Gong, D. Liu, S. Wang, and X. Si, "Experimental simulation analysis of the process and failure characteristics of spalling in D-shaped tunnels under true-triaxial loading conditions," Tunnelling and Underground Space Technology, vol. 90, pp. 42-61, 2019.

[5] H. Wu, G. Zhao, and W. Liang, "Mechanical properties and fracture characteristics of pre-holed rocks subjected to uniaxial loading: a comparative analysis of five hole shapes," Theoretical and Applied Fracture Mechanics, vol. 105, Article ID 102433, 2020.

[6] R.-H. Cao, C. Wang, R. Yao et al., "Effects of cyclic freezethaw treatments on the fracture characteristics of sandstone under different fracture modes: laboratory testing," Theoretical and Applied Fracture Mechanics, vol. 109, Article ID 102738, 2020

[7] Y. Zhao, L. Zhang, J. Liao, W. Wang, Q. Liu, and L. Tang, "Experimental study of fracture toughness and subcritical crack growth of three rocks under different environments," International Journal of Geomechanics, vol. 20, no. 8, 2020.

[8] M. Cai, P. K. Kaiser, H. Morioka et al., "FLAC/PFC coupled numerical simulation of AE in large-scale underground excavations," International Journal of Rock Mechanics and Mining Sciences, vol. 44, no. 4, pp. 550-564, 2007.

[9] C. Zhang, C. Pu, R. Cao, T. Jiang, and G. Huang, "The stability and roof-support optimization of roadways passing through unfavorable geological bodies using advanced detection and monitoring methods, among others, in the Sanmenxia Bauxite Mine in China's Henan Province," Bulletin of Engineering Geology and the Environment, vol. 78, no. 7, pp. 5087-5099, 2019.

[10] Y. Zhao, L. Zhang, W. Wang, and G. Cheng, "Experimental study on shear behavior and a revised shear strength model for infilled rock joints," International Journal of Geomechanics, vol. 20, no. 9, 2020.

[11] A. Fakhimi, F. Carvalho, T. Ishida, and J. F. Labuz, "Simulation of failure around a circular opening in rock," International Journal of Rock Mechanics and Mining Sciences, vol. 39, no. 4, pp. 507-515, 2002.

[12] X.-D. Zhao, H.-X. Zhang, and W.-C. Zhu, "Fracture evolution around pre-existing cylindrical cavities in brittle rocks under uniaxial compression," Transactions of Nonferrous Metals Society of China, vol. 24, no. 3, pp. 806-815, 2014.

[13] C. Y. Zhang, Y. X. Wang, H. Ruan, B. Ke, and H. Lin, "The strain characteristics and corresponding model of rock materials under uniaxial cyclic load/unload compression and their deformation and fatigue damage analysis," Archive of Applied Mechanics, vol. 1-16, 2021.

[14] C. Y. Zhang, Y. X. Wang, and T. T. Jiang, "The propagation mechanism of an oblique straight crack in a rock sample and the effect of osmotic pressure under in-plane biaxial compression," Arabian Journal of Geosciences, vol. 13, no. 15, 2020.

[15] Z.-M. He, D. Xiang, Y.-X. Liu, Q.-F. Gao, and H.-B. Bian, "Deformation behavior of coarse-grained soil as an embankment filler under cyclic loading," Advances in Civil Engineering, vol. 2020, no. 3, pp. 1-13, 2020.

[16] R. H. Cao, R. B. Yao, J. J. Meng, Q. B. Lin, H. Lin, and S. Li, "Failure mechanism of non-persistent jointed rock-like specimens under uniaxial loading: laboratory testing," International Journal of Rock Mechanics and Mining Sciences, vol. 132, 2020.

[17] L. Weng, X. Li, A. Taheri, Q. Wu, and X. Xie, "Fracture evolution around a cavity in brittle rock under uniaxial compression and coupled static-dynamic loads," Rock Mechanics and Rock Engineering, vol. 51, no. 2, pp. 531-545, 2018.

[18] Y. L. Zhao, C. S. Zhang, Y. X. Wang, and H. Lin, "Shearrelated roughness classification and strength model of natural rock joint based on fuzzy comprehensive evaluation," International Journal of Rock Mechanics and Mining Sciences, vol. 137, 2021.

[19] R. H. Cao, R. B. Yao, T. Hu, C. S. Wang, K. H. Li, and J. J. Meng, "Failure and mechanical behavior of transversely isotropic rock under compression-shear tests: laboratory testing and numerical simulation," Engineering Fracture Mechanics, vol. 241, 2021.

[20] Z.-M. He, Z.-F. Liu, X.-H. Liu, and H.-B. Bian, "Improved method for determining active earth pressure considering arching effect and actual slip surface," Journal of Central South University, vol. 27, no. 7, pp. 2032-2042, 2020.

[21] S. Y. Wang, L. Sun, C. Yang, and C. A. Tang, "Numerical study on static and dynamic fracture evolution around rock 
cavities," Journal of Rock Mechanics and Geotechnical Engineering, vol. 5, no. 4, pp. 262-276, 2012.

[22] S.-R. Zhang, B. Sun, C. Wang, and L. Yan, "Influence of intermediate principal stress on failure mechanism of hard rock with a pre-existing circular opening," Journal of Central South University, vol. 21, no. 4, pp. 1571-1582, 2014.

[23] X. Fan, X. Jiang, Y. Liu, H. Lin, K. Li, and Z. He, "Local stress distribution and evolution surrounding flaw and opening within rock block under uniaxial compression," Theoretical and Applied Fracture Mechanics, vol. 112, no. 2, Article ID 102914, 2021.

[24] D. Potyondy and P. Cundall, The PFC Model for Rock: Predicting Rock-Mass Damage at the Underground Research Laboratory, Itasca Consulting Group, Minneapolis, USA, 2002.

[25] D. Potyondy and J. Autio, "Bonded-particle simulations of the insitu failure test at olkiluoto," in Proceedings of the 38th US Rock Mechanics Symposium, pp. 1553-1560, Washington D.C., USA, July 2001.

[26] X. Fan, Z. Yang, and K. Li, "Effects of the lining structure on mechanical and fracturing behaviors of four-arc shaped tunnels in a jointed rock mass under uniaxial compression," Theoretical and Applied Fracture Mechanics, vol. 112, no. 2, Article ID 102887, 2021.

[27] R. H. Cao, P. Cao, H. Lin, G. W. Ma, X. Fan, and X. G. Xiong, "Mechanical behavior of an opening in a jointed rock-like specimen under uniaxial loading: experimental studies and particle mechanics approach," Archives of Civil and Mechanical Engineering, vol. 18, no. 1, pp. 198-214, 2018.

[28] G. Kirsch, "Die Theorie der Elastizitat und die Bedürfnisse der Festigkeitslehre," Veit Vereines Deutscher Ingenieure, vol. 42, no. 28 , pp. 797-807, 1898.

[29] W. C. Zhu, J. Liu, C. A. Tang, X. D. Zhao, and B. H. Brady, "Simulation of progressive fracturing processes around underground excavations under biaxial compression," Tunnelling and Underground Space Technology, vol. 20, no. 3, pp. 231-247, 2005.

[30] C. Wang, D. D. Tannant, and P. A. Lilly, "Numerical analysis of the stability of heavily jointed rock slopes using PFC2D," International Journal of Rock Mechanics and Mining Sciences, vol. 40, no. 3, pp. 415-424, 2003.

[31] K. M. Li, Y. H. Li, S. Xu, and L. An, "Method to determine microcosmic parameters of PFC2D numerical calculation model," Journal of Northeastern University (Natural Science), vol. 37, no. 4, pp. 563-567, 2016. 